\title{
A Double in vivo Biotinylation Technique for Objective Assessment of Aging and Clearance of Mouse Erythrocytes in Blood Circulation
}

\author{
Rajiv K. Saxena ${ }^{\mathrm{a}, \mathrm{b}} \quad$ Nitin Bhardwaj ${ }^{\mathrm{a}}$ Sumedha Sachar ${ }^{\mathrm{a}} \quad$ Niti Puri $^{\mathrm{a}}$ Sanjay Khandelwal ${ }^{\mathrm{a}}$ \\ a School of Life Sciences, Jawaharlal Nehru University, \\ ${ }^{\mathrm{b}}$ Faculty of Life Sciences and Biotechnology, South Asian University, New Delhi, India
}

\section{Keywords}

Double in vivo biotinylation - Erythrocyte aging .

Erythrocyte removal · Mouse blood circulation

\section{Summary}

We have recently developed a new technique to objectively identify erythrocyte cohorts of defined age in mouse blood. The technique (termed double in vivo biotinylation, DIB) involves an initial biotinylation of all erythrocytes in circulation, followed after a few days by a second biotinylation, at a lower density, that labels the biotin-negative erythrocytes that have entered since the first biotinylation. The proportions of biotin ${ }^{\text {high }}$, biotin ${ }^{\text {low }}$, and biotin ${ }^{\text {negative }}$ erythrocytes are enumerated by flow cytometry. The DIB technique allows us to track age-related changes on erythrocyte cohorts (Protocol A), and to simultaneously identify very young and older erythrocyte populations in the blood (Protocol B). Using this technique, we have reexamined: i) the relationship between age and buoyant density of erythrocytes, ii) erythrocyte destruction through a random removal mechanism, and iii) the expression of phosphatidylserine on aging erythrocytes. We have also used the DIB technique to study age-related changes in the expression of various markers like CD47 and CD147 and green autofluorescence in aging erythrocyte populations.

\section{Schlüsselwörter \\ Doppelte In-vivo-Biotinylierung · Erythrozytenalterung · Erythrozytenentfernung · Blutzirkulation der Maus}

\section{Zusammenfassung}

Vor kurzem wurde von uns eine Technik entwickelt, um objektiv Erythrozytengruppen von definiertem Alter im Mäuseblut zu bestimmen. Diese als Doppelte In-vivoBiotinylierung (DIB) bezeichnete Technik beinhaltet eine erste Biotinylierung aller Erythrozyten in der Blutzirkulation gefolgt von einer zweiten Biotinylierung wenige Tage später mit einer geringeren Dichte, so dass nur biotinnegative Erythrozyten, die seit der ersten Biotinylierung in die Zirkulation gelangt sind, markiert werden. Die numerischen Verhältnisse von Biotin ${ }^{\text {high }}{ }_{-}$, Biotin ${ }^{\text {low }}$ und Biotin negative - Erythrozyten wurde mittels Durchflusszytometrie bestimmt. Die DIB-Technik ermöglicht uns, altersabhängige Veränderungen in den Erythrozytengruppen nachzuverfolgen (Protokoll A) und gleichzeitig sehr junge und ältere Erythrozytenpopulationen im Blut zu identifizieren (Protokoll B). Mithilfe dieser Technik prüften wir nochmals 1) die Beziehung zwischen Alter und elastischer Dichte der Erythrozyten, 2) die Erythrozytenzerstörung durch einen wahllosen Entfernungsmechanismus und 3) die Expression von Phosphatidylserin auf alterenden Erythrozyten. Außerdem benutzten wir die DIB-Technik, um altersabhängige Veränderungen in der Expression von verschiedenen Markern wie CD47 und CD147 und bei der grünen Autofluoreszenz von alternden Erythrozytenpopulationen zu studieren.

\section{KARGER

Prof. Dr. Rajiv K. Saxena

Faculty of Life Sciences and Biotechnology

South Asian University, ChanakyaPuri

New Delhi 110021, India

Tel. +91 1124122510

rksaxena@sau.ac.in 


\section{The Double in vivo Biotinylation Technique}

The average life span of mouse erythrocytes is about 60 days [1]. Thus, about $2 \%$ of circulating erythrocytes are replenished daily. We have developed a double in vivo biotinylation (DIB) technique as an objective tool for studying erythrocyte aging in the blood circulation [2-5]. This technique can be used with 2 discreet protocols. Protocol A can be used to track age-related changes in a cohort of erythrocytes released in blood circulation over a defined period - generally 5 days. Principle of this protocol has been depicted in figure 1A. In this protocol, the first biotinylation step, comprising 3 daily intravenous (i.v.) injections of $1 \mathrm{mg} \mathrm{BXN}$ (biotin-X-NHS ester), results in biotinylation of all erythrocytes in the circulation. The mouse is then rested for 5 days. Erythrocytes that freshly enter the blood during this period are biotin negative. At this stage a single i.v. injection of $0.6 \mathrm{mg}$ BXN labels the freshly released biotin ${ }^{\text {negative }}$ erythrocytes to become biotin ${ }^{\text {low }}$ as compared to older biotin ${ }^{\text {high }}$ erythrocytes that were labeled in the first biotinylation step. Any time thereafter, blood erythrocytes isolated from a DIB-labeled mouse may be categorized into 3 groups: biotin ${ }^{\text {high }}$ (oldest age group), biotin ${ }^{\text {low }}$ (defined cohort of erythrocytes released over 5 days) and biotinnegative (youngest erythrocytes). Biotin ${ }^{\text {high }}$, low and negative erythrocytes in blood can be identified by staining with fluorescently labeled streptavidin followed by flow cytometry. Figure $1 \mathrm{~B}$ shows the flow cytometric patterns of biotin labeling on erythrocytes isolated after different steps in the DIB technique. By gating on any category of erythrocytes and using a second or a third staining antibody, it is possible to compare the expression of various markers of interest on the oldest, intermediate and the youngest erythrocyte populations. Furthermore, as the DIB mouse ages, the biotin ${ }^{\text {low }}$ cohort of erythrocytes gradually moves from very young to very old part of the spectrum. By analyzing test bleeds from DIB-labeled mice taken at various time points, it is possible to track changes taking place in the biotin ${ }^{\text {low }}$ cohort of erythrocytes in blood. We have shown that the biotin label on erythrocytes is very stable and does not change once the cells are labeled [2]. The biotin ${ }^{\text {low }}$ cohort of erythrocytes can therefore be followed through at all stages of aging.

Using the alternative DIB Protocol B, very young and very old erythrocytes in blood circulation can be simultaneously analyzed (fig. 2A). In this protocol, mice after the first biotinylation step are rested for 30 days, and the second biotinylation step is then carried out. Mice are killed 10 days after the second biotinylation step. Figure 2B shows that 3 different groups of erythrocytes can be demarcated based on the biotin label. Biotin ${ }^{\text {high }}$ erythrocytes represent erythrocytes that are $>40$ days old, the biotin ${ }^{\text {low }}$ erythrocytes represent 10 - to
Fig. 1. Protocol $\mathrm{A}$ of double in vivo biotinylation (DIB) technique. A Principle of the technique. Normal circulating erythrocytes are biotin negative (a). After 3 daily intravenous (i.v.) injections of BXN (Biotin-X-NHS, $1 \mathrm{mg} / \mathrm{mouse} /$ day), all erythrocytes become biotin labeled (b). After 5 days, newly generated erythrocytes (about $10 \%$ of all erythrocytes) are biotin $^{\text {negative }}$ (c). A second biotinylation step with a single injection of $0.6 \mathrm{mg} \mathrm{BXN}$ results in low biotinylation of freshly generated erythrocytes (d). At all later time points, 3 populations of circulating erythrocytes can be identified based upon their extent of biotinylation (e). B Representative flow cytometric histograms of erythrocytes at various stages shown in A. For this analysis, surface biotin on erythrocytes was revealed by staining with streptavidin coupled to fluorescein isothiocyanate (FITC) or phycoerythrin (PE). In histogram (e) in B, cells were analyzed 5 days after the second biotinylation step, and an accumulation of fresh erythrocytes entering the blood during these 5 days (about $12 \%$ ) is clearly seen as the biotin ${ }^{\text {negative }}$ cells.
Double in vivo Biotinylation (DIB) Technique Simultaneous Identification of young and old RBCs (Protocol A)

(A)

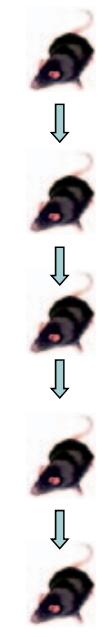

ERYTHROCYTES

a

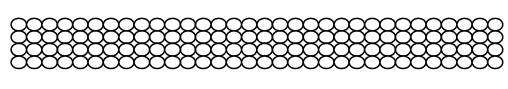

1st Biotinylation step

b

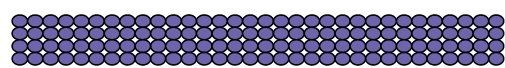

Wait 5 days

c

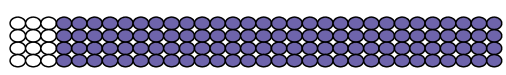

$2^{\text {nd }}$ Biotinylation step

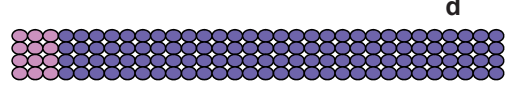

I) After several days Erythrocyte

cohort
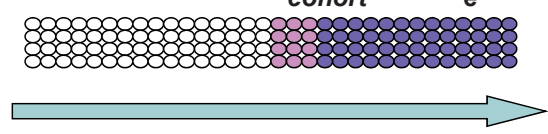

TIME

○ Biotin negative Biotin-High
RBC
B

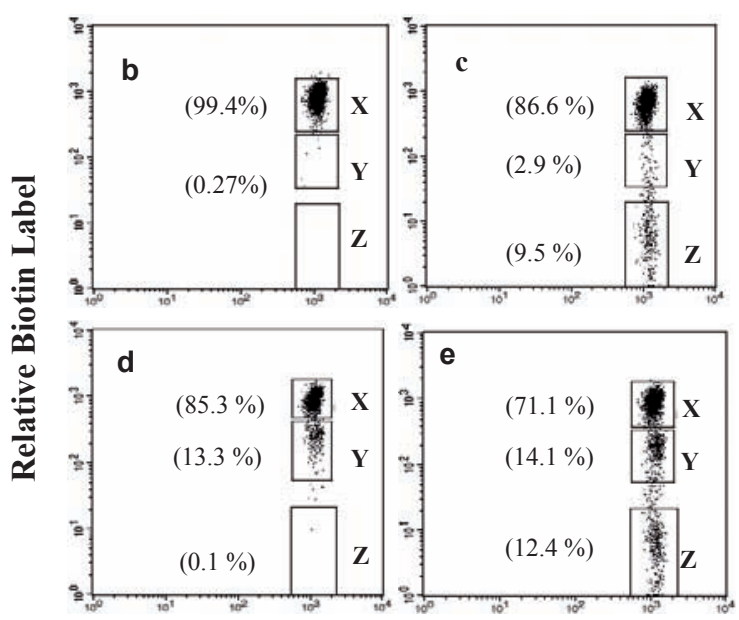

Forward Scatter 
Fig. 2. Protocol B of the DIB technique. A Principle of the technique. Normal circulating erythrocytes are biotin ${ }^{\text {negative }}$ (a). After 3 daily intravenous injections of BXN (1 mg/ mouse/day), all erythrocytes become biotin labeled (b). After 30 days, newly generated erythrocytes are biotin ${ }^{\text {negative }}$ (c). A second biotinylation step with a single injection of $0.6 \mathrm{mg}$ BXN results in low biotinylation of freshly generated erythrocytes (d).

10 days after the second biotinylation, blood erythrocytes have 3 populations of erythrocytes: biotinhigh (age $>40$ days), biotin $^{\text {low }}$ (age 10-40 days) and biotin $^{\text {negative }}$ (age $<10$ days) (e). $\mathbf{B}$

Representative flow cytometric histograms of erythrocytes at stage (e) in $\mathbf{A}$.
Double in vivo Biotinylation (DIB) Technique

Simultaneous Identification of young and old RBCs (Protocol B)
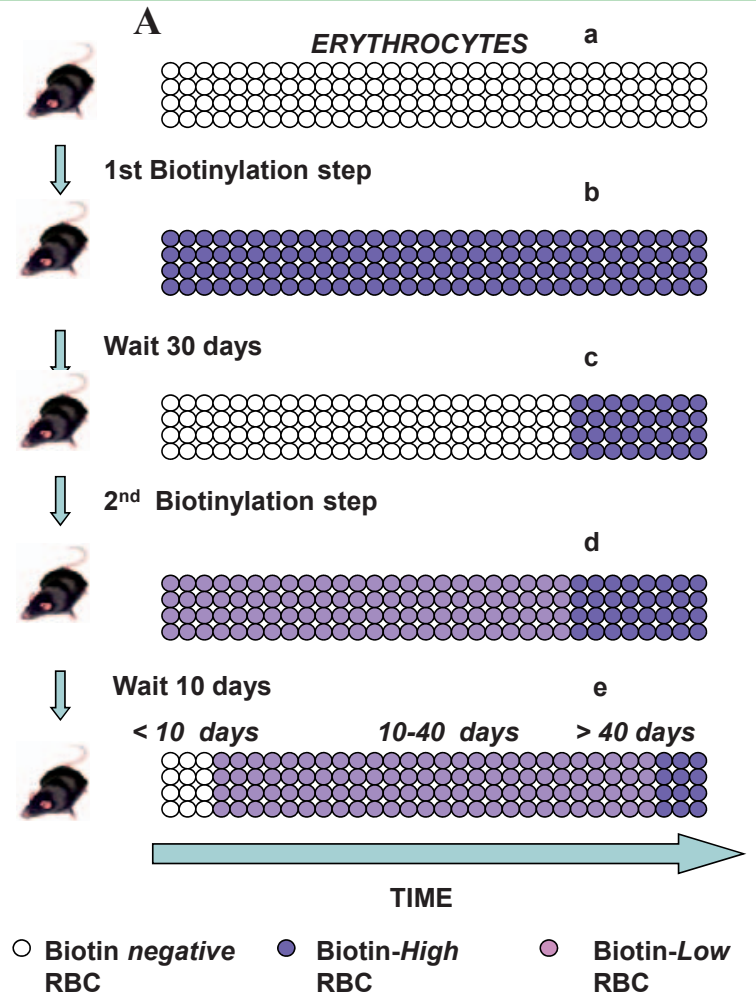

B

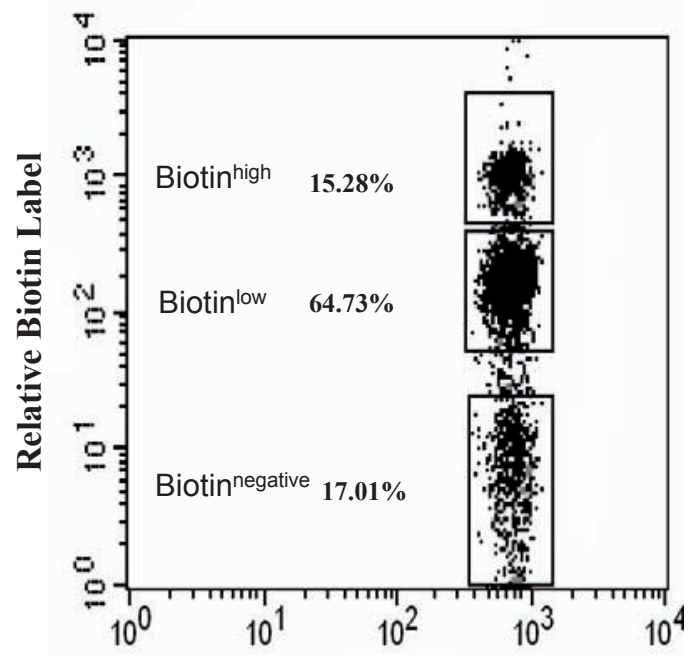

Forward Scatter 40-day-old erythrocytes and the biotin ${ }^{\text {negative }}$ group are young erythrocytes of less than 10 days of age. Thus, Protocol B can be used to distinguish the youngest and oldest erythrocytes in the circulation.

\section{Relationship between Aging and Buoyant Density of Blood Erythrocytes}

Many earlier studies focused on determining age-related changes in circulating erythrocytes [6-9]. Through studies involving buoyant density-based separation of Fe59-labeled human erythrocytes, Borun et al. [10] suggested that the buoyant density of erythrocytes increases as a function of age. This idea caught on and was supported by many subsequent reports [11-13]. Today, however, this idea is controversial and doubts have been raised about the validity of a correlation between the buoyant density of erythrocytes and their age [14, 15]. The properties of high- and low-buoyant density fractions of blood erythrocytes have often been ascribed to old and young erythrocytes respectively. Since our DIB technique can be used to objectively identify the old and young erythrocytes in blood circulation, this technique was used to revisit the issue of relationship between the age of erythrocytes in circulation and their buoyant densities. Mouse erythrocytes were labeled with biotin following Protocol B, which yields a biotinnegative population of erythrocytes that have been less than 10 days in the circulation and biotin ${ }^{\text {high }}$ cells that have been $>40$ days in the circulation. These DIB-labeled erythrocytes were fractionated on a 5-layered percoll density gradient (PDG) and the proportions of biotin ${ }^{\text {negative }}$ and biotin ${ }^{\text {high }}$ erythrocytes were determined in each PDG fraction.

Table 1 shows the recoveries of young (biotin ${ }^{\text {negative }}$ ) and old (biotin ${ }^{\text {high }}$ ) erythrocytes in different percoll fractions. These results clearly show that both young and old erythrocytes are present in all fractions and are not restricted to the light and heavy percoll fractions respectively. Further, the peak absolute recoveries of both young and old erythrocytes occur in fraction 5. Young/old erythrocyte ratios, however, decrease from the lightest to the heaviest fractions. Although fractions 1 and 2 have young/old ratio of 14.33 and 21.98, respectively, indicating a considerable enrichment of young erythrocytes, these 2 fractions accounted of less than $3 \%$ of the total combined erythrocyte recovery in the 6 percoll fractions. Our results thus clearly show that, while the lightest percoll fractions are significantly enriched in young erythro- 
Table 1. Recovery of young and old erythrocytes in different PDG fractions

\begin{tabular}{llcccr}
\hline Fraction & $\begin{array}{l}\text { Buoyant density } \\
\mathrm{mg} / \mathrm{ml}\end{array}$ & \multicolumn{2}{l}{ Erythrocytes recovery $\times 10^{6}$} \\
\cline { 3 - 6 } & \multicolumn{1}{l}{ total } & young $\left(\right.$ bioti $\left.^{\text {negative }}\right)$ & old $\left(\right.$ bioti $\left.^{\text {high }}\right)$ & young/old ratio \\
\hline 1 & $<1.0650$ & $35.43 \pm 2.98$ & $8.74 \pm 0.81$ & $0.61 \pm 0.06$ & 14.33 \\
2 & $1.0650-0.0040$ & $45.53 \pm 4.43$ & $14.73 \pm 1.91$ & $0.67 \pm 0.10$ & 21.98 \\
3 & $1.0711-1.0782$ & $100.50 \pm 24.87$ & $27.60 \pm 2.66$ & $4.96 \pm 2.06$ & 5.56 \\
4 & $1.0782-1.0858$ & $589.00 \pm 52.12$ & $105.34 \pm 15.30$ & $59.87 \pm 8.70$ & 1.76 \\
5 & $1.0858-1.0883$ & $2577.50 \pm 38.95$ & $272.53 \pm 58.83$ & $562.85 \pm 67.63$ & 0.48 \\
6 & $>1.0883$ & $153.88 \pm 19.09$ & $18.92 \pm 1.18$ & $28.68 \pm 4.09$ & 0.65 \\
Unfractionated & & $5,099.20 \pm 92.28$ & $737.06 \pm 142.78$ & $990.62 \pm 93.93$ & 0.74 \\
\hline
\end{tabular}

Mouse erythrocytes were biotinylated as per Protocol B and fractionated on a Discontinuous PDG with five layers of densities ., $0650 \pm 0.004,1.0711 \pm 0.006,1.0782 \pm 0.008,1.0858 \pm 0.004$ and $1.0883 \pm 0.003 \mathrm{~g} / \mathrm{ml}$ prepared as described before [19]. Erythrocytes in different buoyant density fractions were stained with streptavidin-APC followed by flow cytometric analysis. Young and old popuations of erythrocytes (biotin ${ }^{\text {high }}$ and biotin ${ }^{\text {negative }}$, respectively) were enumerated flow cytometrically. Each value represents the mean \pm SEM of data from 4 mice.
Fig. 3. Age-dependent decline in an aging erythrocyte cohort in the blood circulation. C57BL/6 mice were labeled using DIB Protocol A. Blood samples were taken at different times after the second biotinylation step, and the aging cohort (biotin $^{\text {low }}$ population) enumerated by flow cytometry as described in legend to figure 1. Decay of a giving erythrocyte cohort was studied at 5 to 6 time points each in 14 mice. Combined data from 14 mice show the decay of the biotin $^{\text {low }}$ cohort of erythrocytes as a function of age. Correlation coefficients and slopes of the 3 phases of the decay curve are shown.
Fitting equation " $y=m x+c$ " for three phases of erythrocyte loss

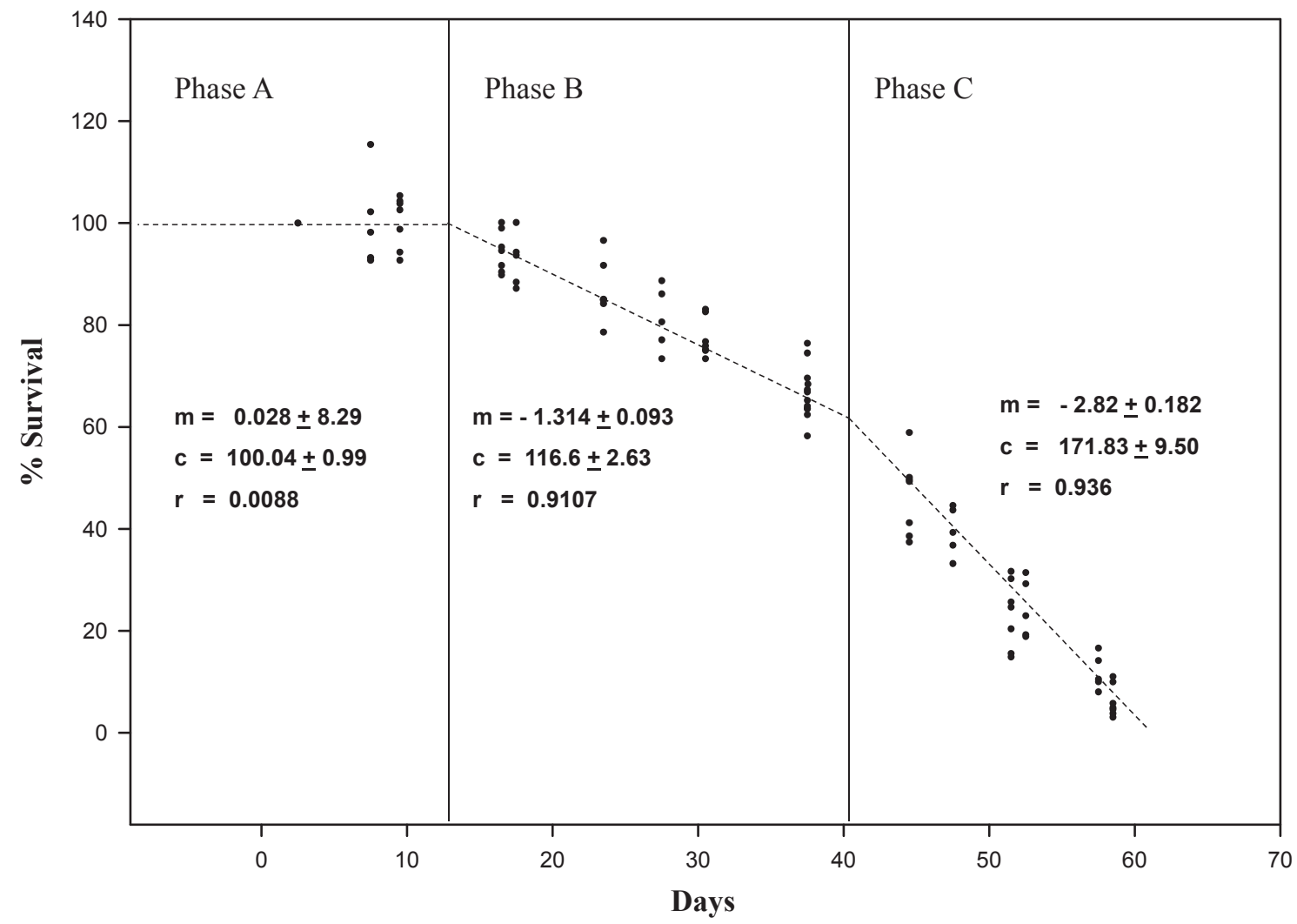

cytes, young erythrocytes in these fractions do not represent the whole young erythrocyte population as more than $97 \%$ of the young erythrocytes are present in heavier fractions. Similarly, old erythrocytes are not significantly enriched in heaviest fractions (young/old ratios 0.48 and 0.65 , table 1 ). Thus, considering the lightest and heaviest fractions of erythrocytes as young and old erythrocyte populations is not a valid proposition as all percoll fractions have both young and old erythrocytes in varying proportions.

\section{Random Elimination of Erythrocytes versus Elimination of Aged Erythrocytes in Blood Circulation}

The average life span of erythrocytes in circulation is about 60 days in mice [1] and 120 days in humans. It is, however, not clear if mouse erythrocytes gradually age in mouse blood and are removed from the circulation after about 60 days or whether the removal of erythrocytes is random, with the length of time in the circulation not playing much role in their removal. 
Fig. 4. Effect of single-walled carbon nanotube (SWCNT) administration on the relative proportions of young and old erythrocytes in mouse blood. Blood erythrocytes were biotinylated using the DIB Protocol B. An acidfunctionalized poly-dispersed preparation of SWCNTs $(100 \mu \mathrm{g})$ was administered i.v. and proportions of young, intermediate, and old erythrocytes were enumerated as described in figure 2. Each data point represents mean \pm standard error of the mean of data from 5 Swiss mice. ${ }^{*} \mathrm{p}<0.05$ as compared to control groups by ANOVA.

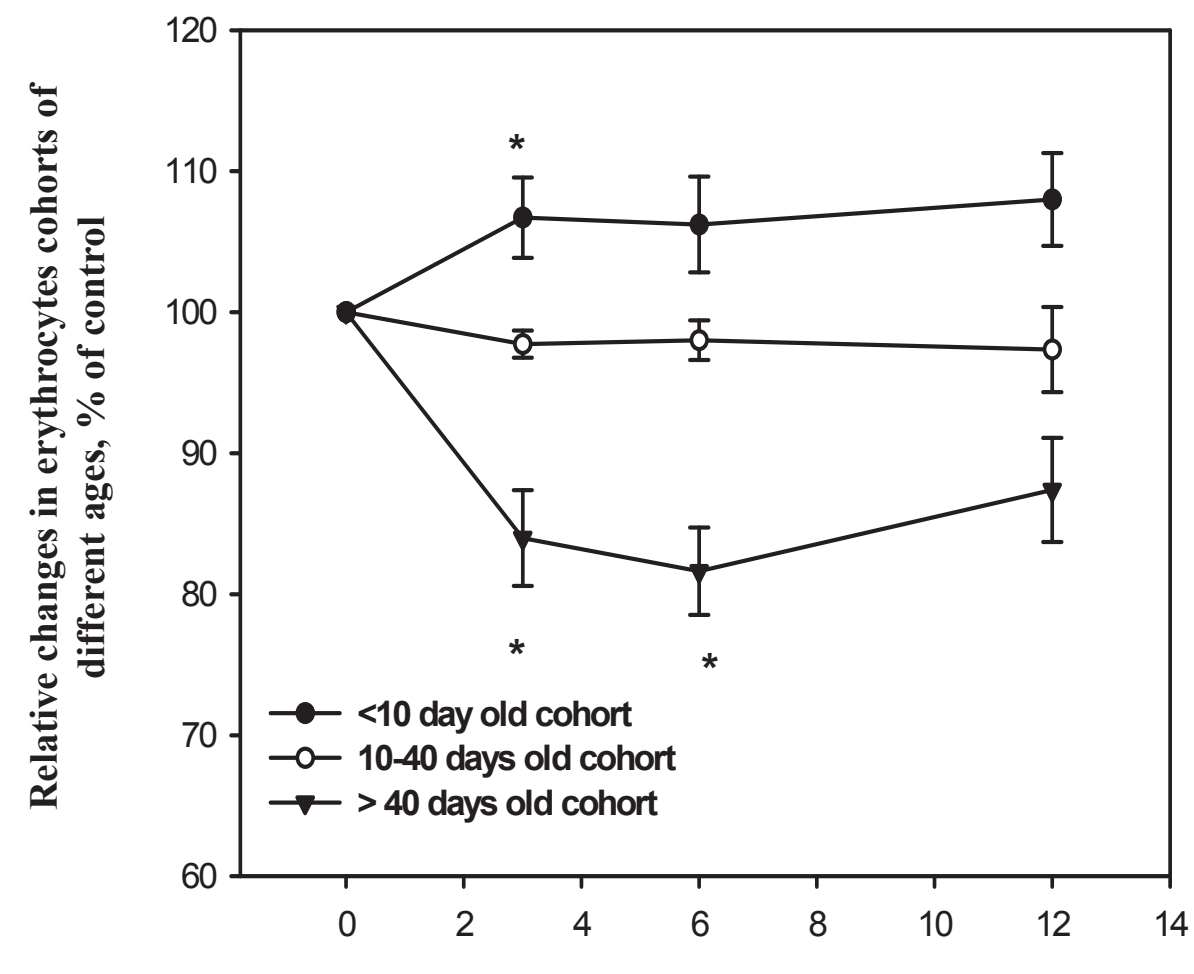

Time, h
Using the DIB technique, we looked at whether the removal of erythrocytes in mouse blood represents random removal, or specific removal of only old erythrocytes. In mice that had been DIB labeled using Protocol A, the biotin ${ }^{\text {low }}$ population denotes a population that has been released into blood over a 5-day period. The aging of this cohort of erythrocytes could be tracked and enumerated using flow cytometry. Combined data from 14 mice for the biotin ${ }^{\text {low }}$ cohort in relation to the aging process are summarized in figure 3 . These results show that over the first 10 days in the circulation, the biotin ${ }^{\text {low }}$ erythrocyte cohort does not decrease in number, indicating that they are not killed in the blood circulation. From days 10 to 40, the cohort decreases in number at a rate of $1.2 \%$ per day. After day 40 , the rate of decrease in the aging erythrocyte cohort increases to about $2.8 \%$ per day.

These results can be interpreted as follows: i) From 0 to 10 days after their release in the blood, erythrocytes are not lost, indicating that there is no random removal for this group of erythrocytes; ii) although between 10 and 40 days the erythrocytes have not yet reached their peak age (about 50 days), this group of erythrocytes is eliminated at a relatively low rate of $1.2 \%$ per day, indicating that in this age group, random loss of erythrocytes does occur; and iii) for erythrocytes above 40 days of age, the loss of biotin ${ }^{\text {low }}$ cohort increases to about $2.8 \%$ per day. The higher rate of death in this age group of erythrocytes may be due to a higher amount of damage that accumulates with the advancing age of cells.

\section{Aging of Erythrocytes and Susceptibility to Carbon Nanotubes}

We have recently shown that the administration of poly-dispersed single-walled carbon nanotubes (SWCNTs) induces transient anemia in mice [16]. DIB mice were used to assess the relative susceptibility of young and old erythrocytes to SWCNTs. Mice subjected to DIB Protocol B were administered SWCNTs and the kinetics of changes in the relative proportions of young (age $<10$ days) and old (age $>40$ days) in the blood circulation was assessed. Results shown in figure 4 indicate that immediately after the administration of SWCNTs, the proportion of old erythrocytes in the blood decreased, while that of young erythrocytes increased. Old erythrocytes thus appear to be more susceptible to SWCNTs. It should be noted that at each time point, the relative change in all 3 erythrocyte populations is shown taking the control proportion of these populations as 100 in each case. A change in 1 population would alter the proportion of other populations in the blood circulation. A relative increase in the proportion of young erythrocytes could be a passive reflection of a decline in the old erythrocyte population. It is also possible that the increase in the relative proportion of young erythrocytes could represent a homeostatic response to anemia. 
Fig. 5. Kinetics of age-dependent changes in the green autofluorescence of blood erythrocytes. Erythrocytes were biotinylated using DIB Protocol A, and at different time points the biotin ${ }^{\text {low }}$ cohort was examined for green autofluorescence (FITC window in flow cytometry). For comparison, average green autofluorescence for all erythrocytes is also shown. Each point represents mean fluorescence intensities (MFI) of the green autofluorescence \pm standard deviation of observations on 5 mice.

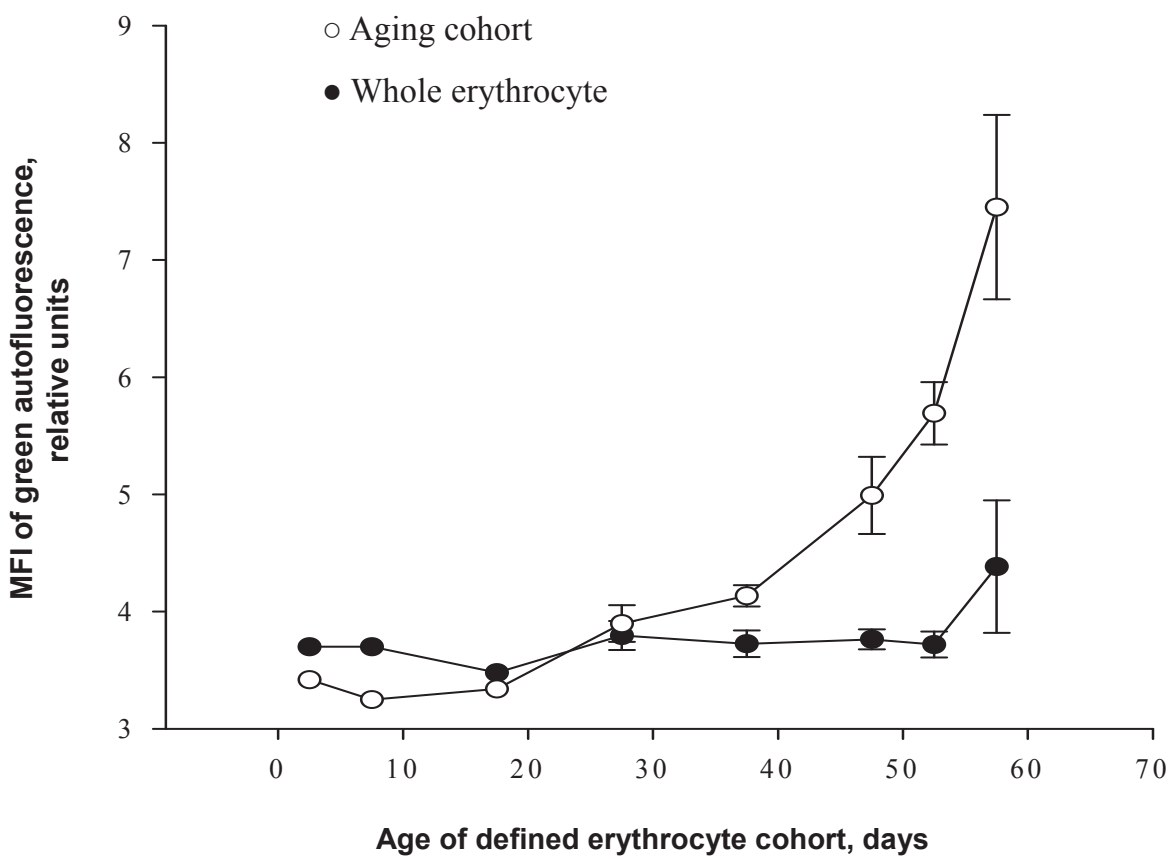

rescence of aged erythrocytes overlaps with the emission spectrum of fluorescein isothiocyanate (FITC). As a result, using an antibody marker to study erythrocyte aging may give erroneous results if FITC-tagged monoclonal antibodies are used. In an earlier report, enhanced PS externalization was demonstrated on aged populations of erythrocytes using FITC-tagged annexin [4]. Although we could reproduce these results, we found that if phycoerythrin (PE)-tagged annexin was used to detect PS, no change in PS expression was found on aged erythrocytes [19].

We have also used DIB Protocol A to track changes in the expression of some important phenotypic markers like CD47 and CD147 on aging erythrocyte cohorts [2-4]. We have employed the DIB technique to study the alterations in aging pattern of circulating erythrocytes in mice subjected to different types of stress and certain infections. This work is in progress.

\section{Conclusion}

Our DIB technique, developed to study erythrocyte aging in vivo, provides an objective tool for identifying and analyzing erythrocyte cohorts of defined age. Using this technique we have found no clear link between the age of erythrocytes and their buoyant density. Loss of erythrocytes from the circulation occurs by both random erythrocyte elimination mechanisms and preferential removal of aged erythrocyte populations; random removal is more pronounced during the earlier phase of erythrocyte presence in blood. No age-related increase in PS was seen in aged erythrocytes, but a spontaneous increase in green autofluorescence was detected on aged erythrocyte cohorts. aging using flow cytometric techniques because the autofluo- 


\section{Acknowledgement}

Funding for this work was obtained through research grants from the Depart of Science and Technology, Government of India, to R.K.S. N.B., S.S. and S.K. received fellowship support from CSIR. Figures used in the review have been modified from various publications $[2-5,16]$. Data in table 1 is unpublished.

\section{Disclosure Statement}

The authors did not provide a conflict of interest statement.

\section{References}

1 Waugh RE, Naria M, Jackson CW, Mueller TJ, Suzuki T, Dale GL: Rheologic properties of senescen erythrocytes: Loss of surface area and volumewith red blood cell age. Blood 1992;79:1351-1358.

2 Khandelwal S, Saxena RK: Assessment of survival of aging erythrocyte in circulation and attendant changes in size and CD147 expression by a novel two step biotinylation method. Exp Gerontol 2006; 41:855-861.

3 Khandelwal S, van Rooijen N, Saxena RK: Reduced expression of CD47 during murine red blood cell (RBC) senescence and its role in RBC clearance from the circulation. Transfusion 2007;47: $1725-1732$.

4 Khandelwal S, Saxena RK: A role of phosphatidylserine externalization in clearance of erythrocytes exposed to stress but not in eliminating aging populations of erythrocyte in mice. Exp Gerontol 2008; 43:764-770.

5 Saxena RK, Khandelwal S: Aging and destruction of erythrocytes in mice. Curr Sci 2009;97:500-507.

6 Prankerd TA: The ageing of red cells. J Physiol 1958;143:325-331.

7 Rigas DA, Koler RD: Erythrocyte enzymes and reduced glutathione (GSH) in hemoglobin $\mathrm{H}$ disease: Relation to cell age and denaturation of hemoglobin H. J Lab Clin Med 1961;58:417-424.
Garby L, Hjelm M: Ultracentrifugal fractionation of human erythrocytes with respect to cell age. Blut 1963;9:284-291.

9 Piomelli S, Lurinsky G, Wasserman LR: The mechanism of red cell aging. Relationship between cell age and specific gravity evaluated by ultracentrifugation in a discontinuous density gradient. J Lab Clin Med 1967;69:659-674.

10 Borun ER, Figueroa WG, Perry SM: The distribution of Fe59 tagged human erythrocytes in centrifuged specimen as a function of cell age. J Clin Invest 1957;36:676-679.

11 Greenwalt TJ, Flory LL, Steane EA: Quantitative haemagglutination. III. Studies of separated populations of human red blood cells of different densities. Br J Haematol 1970;19:701-709.

12 O'Connell DJ, Caruso CJ, Sass MD: Separation of erythrocytes of different ages. Clin Chem 1965;11: 771-781

13 Prentice TC, Bishop C: Separation of rabbit cells by density methods and characteristics of separated layers. J Cell Physiol 1965;65:113-125.
14 Rennie CM, Thompson S, Parker AC, Maddy A Human erythrocyte fractionation in 'Percoll' density gradients. Clin Chim Acta 1979;98:119-125.

15 Morrison M, Jackson CW, Mueller TJ, Huang T, Dockter ME, Walker WS, Singer JA, Edwards HH: Does red cell density correlate with cell age? Biomed Biochem Acta 1983;42:107.

16 Sachar S, Saxena RK: Cytotoxic effect of poly-dispersed single walled carbon nanotubes on erythrocytes in vitro and in vivo. PLoS One 2011;6:e22032.

17 Saxena RK, Chandrasekhar B: A novel non-phagocytic mechanism of erythrocyte destruction involving direct cell mediated lysis. Int J Hematol 2000; 71:227-237.

18 Saxena RK: Should erythrocyte destruction in vivo be through phagocytosis alone? J Biosci 2000;25:3-5.

19 Khandelwal S, Saxena RK: Age dependent increase in green autofluorescence of blood erythrocytes. J Biosci 2007;32:1139-1145.

20 Magnani M, Rossi L, Stocchi V, Cucchiarini L, Piacentini G, Fornaini G: Effect of age on some properties of mice erythrocytes. Mech Ageing Dev 1988;42:37-47. 